\title{
Localized electron density enhancements in the high-altitude polar ionosphere and their relationships with storm-enhanced density (SED) plumes and polar tongues of ionization (TOI)
}

\author{
Y. Kitanoya ${ }^{1}$, T. Abe ${ }^{2}$, A. W. Yau ${ }^{3}$, T. Hori ${ }^{4}$, and N. Nishitani ${ }^{4}$ \\ ${ }^{1}$ University of Tokyo, Hongo, Tokyo, Japan \\ ${ }^{2}$ Japan Aerospace Exploration Agency, Institute of Space and Astronautical Science, Sagamihara, Kanagawa, Japan \\ ${ }^{3}$ University of Calgary, Department of Physics and Astronomy, Calgary, Alberta, Canada \\ ${ }^{4}$ Solar-Terrestrial Environment Laboratory, Nagoya University, Furou-cho, Chikusa, Nagoya, Aichi, Japan
}

Received: 19 August 2010 - Revised: 20 December 2010 - Accepted: 7 February 2011 - Published: 21 February 2011

\begin{abstract}
Events of localized electron density increase in the high-altitude $(>3000 \mathrm{~km})$ polar ionosphere are occasionally identified by the thermal plasma instruments on the Akebono satellite. In this paper, we investigate the vertical density structure in one of such events in detail using simultaneous observations by the Akebono and DMSP F15 satellites, the SuperDARN radars, and a network of ground Global Positioning System (GPS) receivers, and the statistical characteristics of a large number $(>10000)$ of such events using Akebono data over half of an 11-year solar cycle. At Akebono altitude, the parallel drift velocity is remarkably low and the $\mathrm{O}^{+}$ion composition ratio remarkably high, inside the high plasma-density regions at high altitude. Detailed comparisons between Akebono, DMSP ion velocity and density, and GPS total electron content (TEC) data suggest that the localized plasma density increase observed at high altitude on Akebono was likely connected with the polar tongue of ionization (TOI) and/or storm enhanced density (SED) plume observed in the F-region ionosphere. Together with the SuperDARN plasma convection map these data suggest that the TOI/SED plume penetrated into the polar cap due to anti-sunward convection and the plume existed in the same convection channel as the dense plasma at high altitude; in other words, the two were probably connected to each other by the convecting magnetic field lines. The observed features are consistent with the observed high-density plasma being transported from the mid-latitude ionosphere or plasmasphere and unlikely a part of the polar wind population.
\end{abstract}

Keywords. Ionosphere (Plasma temperature and density) Magnetospheric physics (Polar cap phenomena)

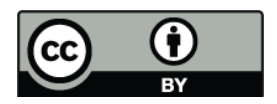

Correspondence to: $\mathrm{T}$. Abe (abe.takumi@jaxa.jp)

\section{Introduction}

The plasma density in the ionosphere in general decreases with altitude, and is lower at high latitude than at middle and low latitudes at a given altitude. It is particularly low in the polar cap ionosphere, due to plasma escape along open magnetic field lines. Kitamura et al. (2009) examined the latitudinal dependence of electron density above $45^{\circ}$ invariant latitude using the plasma wave and sounder (PWS) observations on Akebono, and found the electron density at $\sim 4000 \mathrm{~km}$ altitude to be about $3 \times 10^{3} \mathrm{~cm}^{-3}$ and $2 \times 10^{2} \mathrm{~cm}^{-3}$ at mid$\left(50^{\circ}\right.$ invariant latitude (ILAT)) and high-latitude ( $\left.80^{\circ} \mathrm{ILAT}\right)$, respectively, on the dayside in winter conditions.

Plasma densities in the high-altitude polar cap have been obtained by several methods. The measured electron densities are about $1000 \mathrm{~cm}^{-3}$ at $2000 \mathrm{~km}$ and below $100 \mathrm{~cm}^{-3}$ at $6000 \mathrm{~km}$ on S3-3 (Kletzing et al., 1998), and decrease rapidly with geocentric distance (with a power-law index of 3.85) above $7000 \mathrm{~km}$ on DE-1 near solar maximum (Persoon et al., 1983). The measured ion densities are below $1000 \mathrm{~cm}^{-3}$ at $3500 \mathrm{~km}$ on DE-1 near solar maximum (Chandler et al., 1991), and about $10 \mathrm{~cm}^{-3}$ at $5000 \mathrm{~km}$ on POLAR near solar minimum (Su et al., 1998).

Ichikawa et al. (2002) analyzed Akebono plasma density data over a 10-year period, and reported the occasional occurrence of local plasma density enhancement $\left(>1000 \mathrm{~cm}^{-3}\right)$ above $4000 \mathrm{~km}$ altitude in the polar cap ionosphere, where the electron density is usually on the order of and below $100 \mathrm{~cm}^{-3}$ near solar maximum and minimum, respectively. They also showed that such high-density regions are characterized by a distinctively low electron temperature $(<3000 \mathrm{~K})$ and low parallel ion velocity $\left(\leq 1 \mathrm{~km} \mathrm{~s}^{-1}\right)$. The fact that the electron temperature is about half of the average value at the same altitude (Abe et al., 1993b) suggests that energetic particle precipitation is probably not responsible for

Published by Copernicus Publications on behalf of the European Geosciences Union. 
the electron density enhancement. The low ion velocity is in direct contrast to the typical behavior of the polar wind, in which the $\mathrm{H}^{+}$ion velocity typically increases with altitude, from $\sim 5 \mathrm{~km} \mathrm{~s}^{-1}$ at $3000 \mathrm{~km}$ to $\sim 8 \mathrm{~km} \mathrm{~s}^{-1}$ at $6000 \mathrm{~km}$ (Abe et al., 1993b). Ichikawa et al. (2002) suggested that the plasma density enhancements in the high-altitude polar cap may originate from dense plasma produced by solar EUV photo-ionization in the dayside or particle precipitation in the cusp under anti-sunward convection. However, this in itself cannot explain the rare occurrence of such density enhancements.

There are several sub-categories of F2-region electron density enhancement events in the literature, such as "storm enhanced density" (SED), "polar tongues of ionization" (TOI), and "polar patches". The term "storm enhanced density" (SED) refers to a plasma plume observed from groundbased radars and GPS networks that is streaming from the post-noon or pre-midnight sub-auroral ionosphere towards the cusp (Foster, 1993; Foster et al., 2004). Although SED is most clearly seen during magnetic storms, when the convection electric field expands to relatively low latitudes, it is also identified at Kp levels as low as 2 (Foster, 1993). The term "tongue of ionization" (TOI) refers to a local density enhancement of low-temperature plasma in the F-region polar ionosphere (Foster et al., 2005). The term "polar patch" refers to the local increase of electron density in the F-region auroral ionosphere, in which the plasma density is typically a factor of 2-10 higher than the surrounding density (Weber et al., 1984; Coley and Heelis, 1995) over a horizontal extent on the order of $200-1000 \mathrm{~km}$.

A low-altitude signature of plasmaspheric drainage plumes, the SED is mapped into an extended plasmaspheric tail stretching toward the noontime magnetopause (Foster et al., 2002; Su et al., 2001). With the merging of the subauroral polarization stream (SAPS) into the two-cell auroral convection, the TOI is formed as an extension of a SED plume (Hosokawa et al., 2010), and unlike the SED is often observed in the other (later) phases of a magnetic storm. Thereafter, the anti-sunward convection will cause the TOI to traverse the dayside cusp and the polar cap into the nightside (Foster et al., 2005). The occurrence of TOI penetrating deep into the central polar cap is generally rare. However, no direct observations of the high-altitude extension of the TOI plume are available above a few thousand $\mathrm{km}$, although a relationship of an intense SED plume with the plasmaspheric drainage plume has been discussed (Foster et al., 2004).

In this paper, we present a detailed case study of the relationships between local plasma density enhancements at high-altitudes and SED and TOI plumes in the F-region, using simultaneous data from the Akebono and DMSP F-15 satellites, the SuperDARN radars, and a network of ground GPS receivers in one of the observed events; and a statistical study of the characteristic features of localized plasma density enhancements, using the Akebono data in a large number (>10 000) of observed events.

\section{Observations}

\subsection{Akebono observations of local plasma density enhancements}

The Akebono satellite was launched on 22 February 1989, into an elliptical orbit with an initial apogee of $10470 \mathrm{~km}$, a perigee of $272 \mathrm{~km}$, and an inclination of $75^{\circ}$. Data in this study were acquired by the Thermal electron Energy Distribution (TED) and Suprathermal ion Mass Spectrometer (SMS) instruments on Akebono (Abe et al., 1990; Whalen et al., 1990). The TED makes direct measurements of the thermal electron energy distribution from 0 to about $3 \mathrm{eV}$, and the measured distribution can be used to calculate electron temperature and density (Abe et al., 1990). The TED measurements are usually reliable in regions where the plasma density exceeds $1000 \mathrm{~cm}^{-3}$. In its thermal fast scan mode, the SMS measures ions in the $0-20 \mathrm{eV}$ range at 8 retarding potential (RPA) steps for each of 4 selected species $\left(\mathrm{H}^{+}, \mathrm{He}^{+}\right.$, $\mathrm{He}^{++}$or $\mathrm{O}^{++}$, and $\left.\mathrm{O}^{+}\right)$once every $1 / 32$ spin period $(0.25 \mathrm{~s})$. The measured ion data are used to estimate the spin plane component of the parallel ion drift velocity and density of individual species (Abe et al., 1993a). The uncertainties in the electron temperature, ion velocity and density estimates are typically about $20-30 \%, 0.1-0.5 \mathrm{~km} \mathrm{~s}^{-1}$, and $30-50 \%$, respectively. The uncertainties are due to a number of possible sources of error in the TED and SMS measurements, which are discussed in Abe et al. (1990) and Abe et al. (1993a), respectively, and these include the departure of the measured electron and ion distributions from the assumed Maxwellian distributions, the possible presence of highly field-aligned ions outside the SMS field-of-view when the spacecraft spin plane is at an angle to the local magnetic field, and the approximate correction for the effects of spacecraft potential.

In March 1992, the Akebono satellite periodically traversed the polar cap $\left(\geq 80^{\circ}\right.$ ILAT) above $4000 \mathrm{~km}$ in the Southern Hemisphere, where the electron density had been observed by previous satellites to be about or below $100 \mathrm{~cm}^{-3}$ (Persoon et al., 1983) and the electron currents to the TED probe are typically too small to be used for electron density estimation. Figure 1a shows the probe voltage versus time (V-t) spectrogram of the measured secondary harmonic current on 10 March 1992; see Abe et al. (1990) for the detailed relationship between the measured current distribution and the electron energy distribution. In this pass, the TED encountered a very high density region between 17:31 and 17:39 UT. The densities derived from the V-t spectrogram were $\sim 1000 \mathrm{~cm}^{-3}$ at $4500 \mathrm{~km}$ altitude (17:32 UT) and $\sim 2000 \mathrm{~cm}^{-3}$ at $5300 \mathrm{~km}$ altitude (17:38 UT), respectively, as shown in Fig. 1c; these density values were approximately an order of magnitude larger than the averaged density at such altitudes in the polar cap. Furthermore, the electron temperature at 17:38 UT ( $\sim 4000 \mathrm{~K}$ at $5300 \mathrm{~km}$ altitude $)$ inside the high-density region was remarkably low (see Fig. 1b) compared with the temperature of $>8000 \mathrm{~K}$ in the same altitude 
10 MARCH 1992

AKEBONO OBSERVATIONS, 17:24-17:46 UT

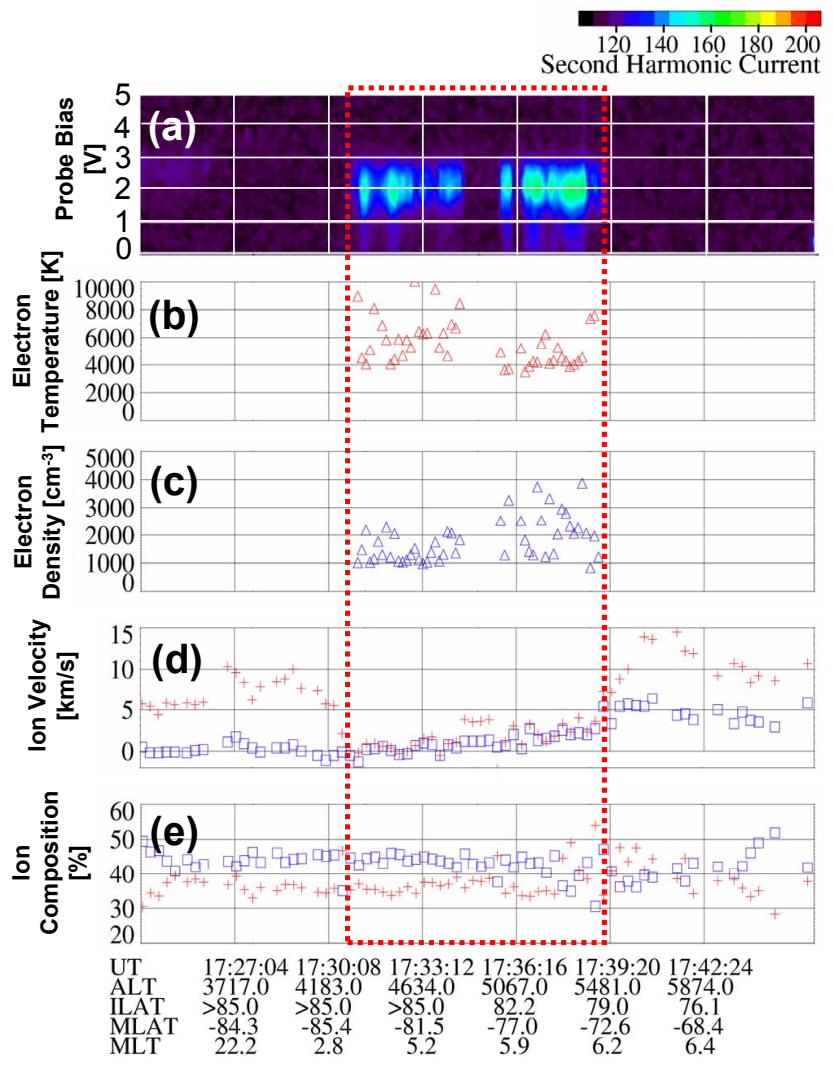

Fig. 1. (a) Probe voltage versus time spectrogram of second harmonic current, (b) electron temperature, (c) electron density on 10 March 1992 derived from TED observations; see text for detailed relationship between the measured current and the electron energy distribution, (d) Parallel drift velocities (positive upward) of $\mathrm{H}^{+}$(red) and $\mathrm{O}^{+}$(blue) ions derived from SMS observations, and (e) $\mathrm{H}^{+}$(red) and $\mathrm{O}^{+}$(blue) fraction of total ion density; the red dashed lines denote the high plasma density region.

range elsewhere in the polar cap (Abe et al., 1993b). Figure $1 \mathrm{~d}$ and e shows the upward field-aligned velocity and density fraction of $\mathrm{H}^{+}$(red crosses) and $\mathrm{O}^{+}$(blue squares) ions. The averaged polar wind $\mathrm{H}^{+}$ion velocity is about $7-$ $8 \mathrm{~km} \mathrm{~s}^{-1}$ at $4000-5000 \mathrm{~km}$ altitude (Abe et al., 1993a). In contrast, the upward $\mathrm{H}^{+}$ion velocity inside the high-density region was very low $\left(0-1 \mathrm{~km} \mathrm{~s}^{-1}\right)$, while those in the surrounding region were close to the averaged value. The $\mathrm{O}^{+}$ velocity tended to increase with altitude but showed no discernible difference inside and outside the high-density region, respectively.

\subsection{Relationship between high-altitude plasma density enhancements and SED/TOI}

In the month of March 2002, the TED on Akebono occasionally encountered high density plasma regions that were
20 MARCH 2002

AKEBONO OBSERVATIONS, 15:30-15:55 UT

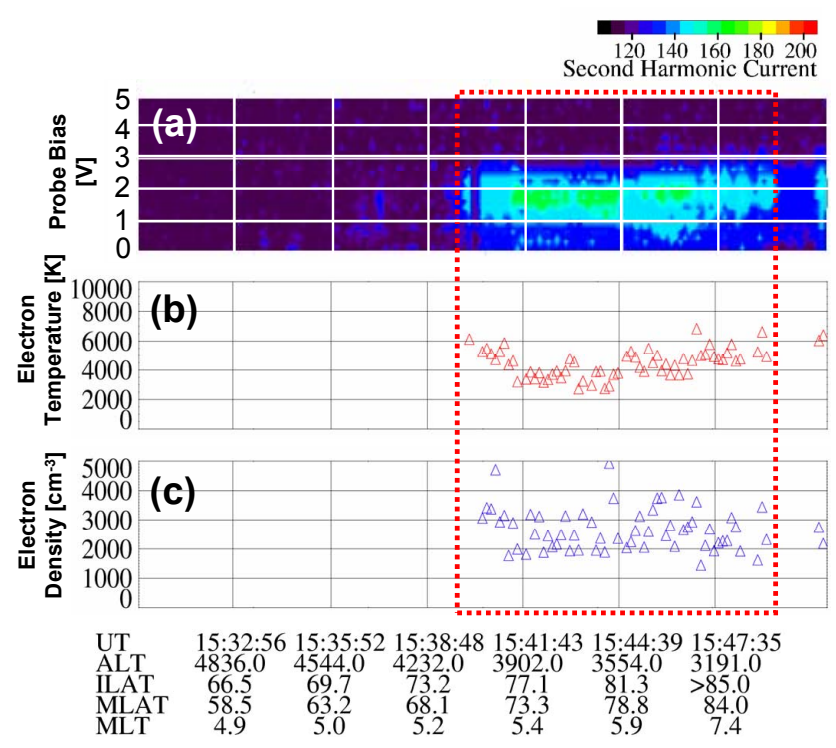

Fig. 2. (a) Probe voltage versus time spectrogram of second harmonic current, (b) electron temperature, and (c) electron density on 20 March 2002 derived from TED observations.

similar to the event in March 1992 shown in Fig. 1. Figure 2 shows the probe voltage versus time $(\mathrm{V}-\mathrm{t})$ spectrogram, the electron temperature and density in one such event during the recovery phase of a magnetic storm on 20 March 2002, when the TED observed a high-density plasma region continuously between 15:40 and 15:49 UT. Using this figure and Figs. 3 and 4 below, we will compare the simultaneous observations of plasma density variation at high altitude on Akebono, thermal ion drift in the F-region on DMSP, the global plasma convection pattern from the SuperDARN radars, and TEC distribution from ground GPS receiver network in this event, in order to investigate the characteristic features of localized plasma density enhancement and its relationship with TOI and/or SED plumes in this particular event.

Figure 3a shows a map of total electron content (TEC) at 15:40-15:45 UT obtained from a network of ground GPS receivers (Rideout and Coster, 2006) in the Northern Hemisphere. This TEC map suggests that a strong plume ( $>40$ TEC units) of SED (Foster, 1993; Foster et al., 2004) (region "A") that was elongated toward the dayside cusp from the post-noon ( $\sim 15 \mathrm{MLT})$ sub-auroral ionosphere, where the vertical TEC may be attributed to the combined contribution of the ionosphere and the overlying plasmasphere. The TEC data in the preceding 2-h period shows that the plume had existed continuously from 14:00 to 15:50 UT. In the downstream region of the plume, a high-density $\left(>1000 \mathrm{~cm}^{-3}\right)$ and low-temperature $(<6000 \mathrm{~K})$ plasma was identified at high altitude at 15:40-15:49 UT by Akebono at $\sim 80^{\circ}$ ILAT $\left(\sim 78^{\circ} \mathrm{MLAT}\right), \sim 5.8 \mathrm{MLT}$, and 

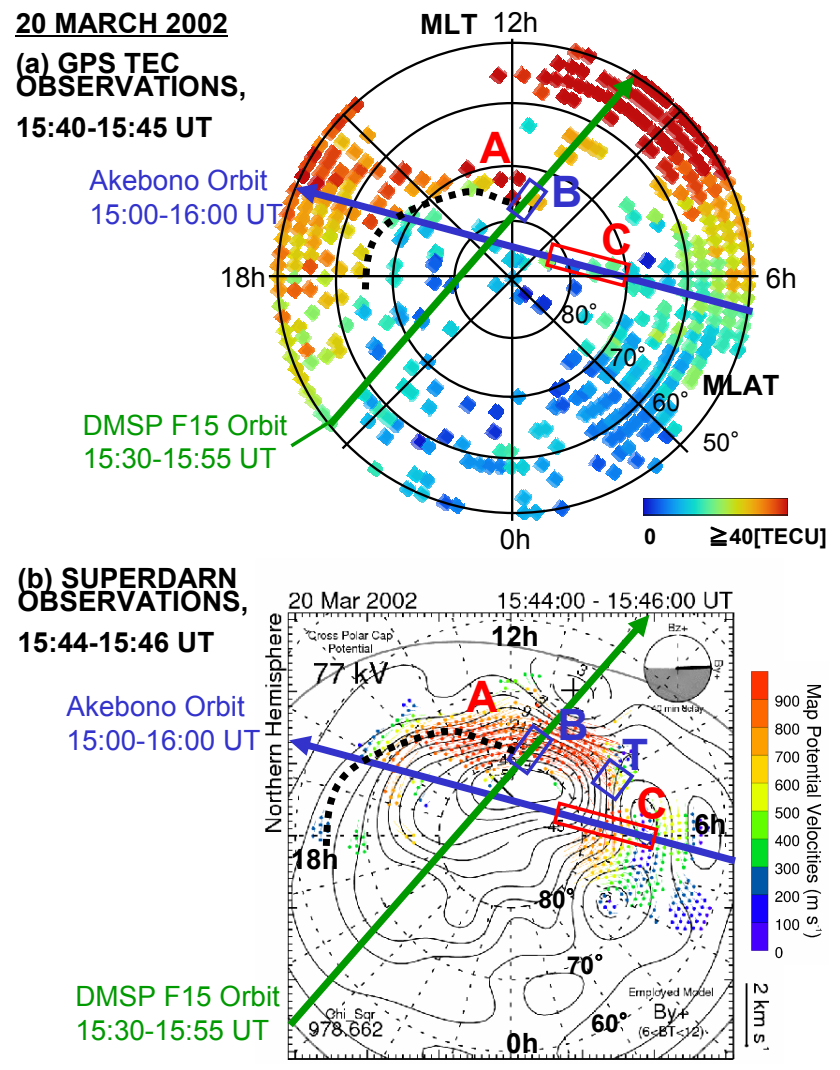

Fig. 3. (a) A map of Total Electron Content (TEC) at 15:4015:45 UT on 20 March 2002 derived from observations from ground GPS receiver network. The black square dots in the afternoon sector denote the contour of $>30$ TEC units (TECU) and the extent of the plume toward the cusp; the corresponding contour in the morning sector is not available due to lack of data. Label "A": region of SED in the GPS-TEC observations; "B": anti-sunward convection region identified by DMSP F15; "C": high plasma density region identified by Akebono; "T": see Sect. 3. (b) A convection map at 15:44-15:46 UT on 20 March 2002 derived from SuperDARN radar observations.

$3000-4000 \mathrm{~km}$ altitude (region "C" in Fig. 3). Unfortunately, ion velocity data are not available for this event because of saturation of $\mathrm{O}^{+}$ion counts in the SMS data and the lack of definitive satellite attitude information in this orbit pass. During this time, the geomagnetic activity was relatively high $(\mathrm{Kp}=4+)$, IMF $B_{\mathrm{y}}$ and $B_{\mathrm{Z}}$ were positive at 15:00 UT.

Figure 4 shows (a) low energy electron flux, (b) horizontal and (c) vertical components of ion drift, and (d) ion number density between 15:30 and 15:55 UT, at about $850 \mathrm{~km}$ altitude on the Defense Meteorological Satellite Program (DMSP) F15 satellite, which was in a Sun-synchronous nearcircular dawn-dusk orbit. The low energy electron flux (a) was observed by the Special Sensor Precipitating Electron and Ion Spectrometer (SSJ/4), and the ion drift velocity components and density $(b-d)$ were observed by the Special Sensor for Ions, Electrons and Scintillation (SSIES) and horizon-
20 MARCH 2002 DMSP F15 OBSERVATIONS, 15:30-15:55 UT

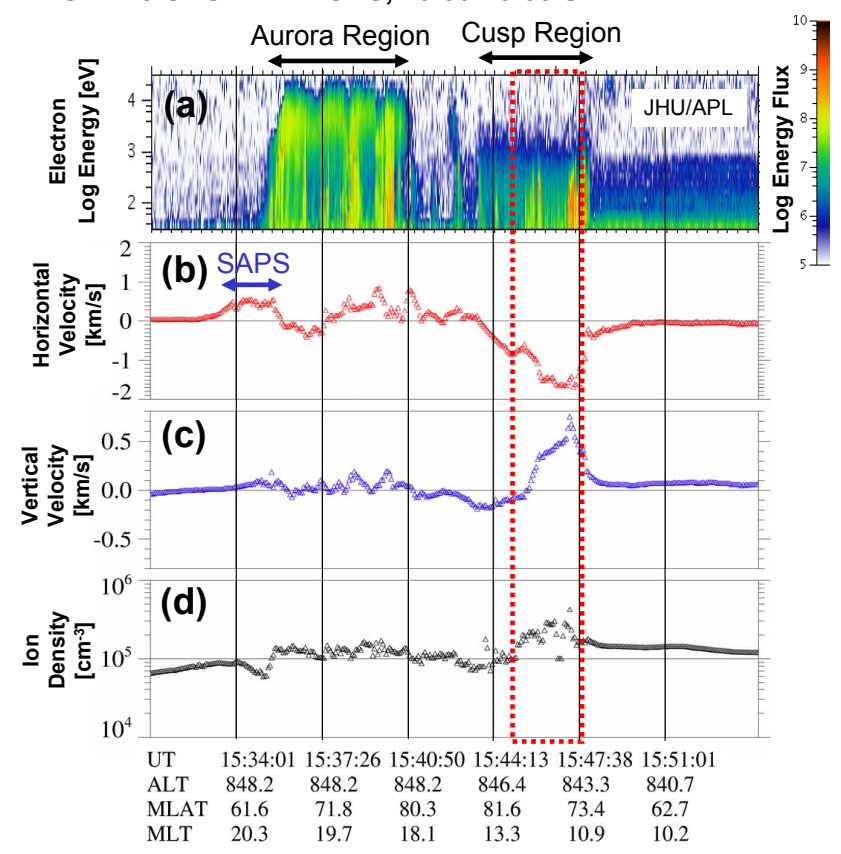

Fig. 4. (a) Low energy electron flux, (b) the horizontal component (positive sunward) and (c) vertical component (positive upward) of ion drift velocity, and (d) ion number density observed by DMSP F15 on 20 March 2002. A region of strong anti-sunward plasma convection is denoted by the dashed lines.

tal Ion Drift Meter (IDM) onboard DMSP F15. Figure 4b shows the presence of a SAPS at $\sim 63^{\circ}$ MLAT, $\sim 20$ MLT between 15:33:30-15:35:30 UT, and this suggests the possibility of the plasma moving poleward from the subauroral region. Figure $4 \mathrm{c}$ and $\mathrm{d}$ shows that in the anti-sunward convection region between 15:45 and 15:48 UT, when DMSP was at $\sim 75.5$ MLAT and $\sim 11.2$ MLT, both the upward component of ion drift and the ion density were enhanced compared with the surrounding region. This anti-sunward convection highdensity region is denoted as region " $\mathrm{B}$ " in Fig. 3a and b.

Figure $3 b$ is a SuperDARN ion convection map (Ruohoniemi and Baker, 1998) of the Northern Hemisphere at 15:44-15:46 UT and it depicts the global convection pattern in the polar ionosphere during this time interval; as confirmed by convection maps in the immediately preceding and proceeding periods (not shown), this convection pattern existed continuously from 15:30 to 16:00 UT. The antisunward convection region identified in the DMSP F15 ion drift data extended from the cusp $(\sim 12$ MLT) towards the morning side $(\sim 09 \mathrm{MLT})$, into the morning-side ( $\sim 06 \mathrm{MLT})$ polar cap ( $>80$ ILAT) region, where Akebono observed the high-density plasma. Thus, it is suggested that the highdensity region observed on Akebono existed in the same anti-sunward convection channel as the TOI plume, but at a higher altitude, and that it is most probably connected with 
the plume through convecting magnetic field lines. Note that the convection velocity was up to $\sim 0.7-0.9 \mathrm{~km} \mathrm{~s}^{-1}$.

Together, Figs. 2-4 suggest that the high density plasma identified on DMSP was likely drifting in the convection channel that carried the TOI plume, in view of the simultaneity of the ion drift and plume observations and the continuous temporal extent of the observed plume. Our comparison of the respective observations from Akebono, DMSP F15, the ground GPS receiver network and SuperDARN indicates that the plume entering the high-latitude polar cap was observed in the cusp region at low altitude by DMSP F15 and in the polar cap at high altitude by Akebono, respectively. Thus, the simultaneous observations reveal the large horizontal and vertical extents of a TOI plume.

\subsection{Statistical features of localized plasma density enhancements}

Thermal plasma data from Akebono between March 1989 and December 1997 were analyzed to investigate the statistical characteristics (occurrence probability and plasma properties) of high density plasma events in which the electron density exceeds $1000 \mathrm{~cm}^{-3}$ and the electron temperature is below $7000 \mathrm{~K}$ at $3000-6000 \mathrm{~km}$ altitude in the polar cap (ILAT $>75^{\circ}$ ). The study did not examine the statistical relationship of the high-density plasma events with the SED/TOI. The total number of TED observations in this altitude-invariant latitude region is 196533 and 304064 during periods of high (1989-1992) and low solar activity (1993-1997), respectively.

The occurrence probability of high density plasma events under a specific set of geophysical conditions was computed as $f=n / N$ where $n$ is the number of events and $N$ is the number of TED observation samples, and the statistical deviation was estimated as $\sigma=\{f(1-f) /(N-1)\}^{1 / 2}$. The following characteristic features were found:

1. At $3000-6000 \mathrm{~km}$ altitude in the polar cap (ILAT $>75^{\circ}$ ), the occurrence probability of highplasma-density events was about $5.1 \%$ (of total TED observations during high solar activity period (9917 events), and only $0.4 \%$ during low solar activity period (1181 events). The probability increased from 1.0\% during quiet times $(\mathrm{Kp}<2)$ to about $4.4 \%$ during geomagnetically active times $(\mathrm{Kp} \geq 4)$ and about $10.2 \%$ during very active times $(\mathrm{Kp} \geqq 6)$. The standard deviation $\sigma$ was $<0.05 \%$ in most cases and $<0.1 \%$ in all cases.

2. During high solar activity, the high-plasma-density region was observed more frequently $(6.6 \%)$ on the duskside (MLT 15-21) than on the dawnside $(2.6 \%$, MLT 03-09), and more frequently (8.6\%) on the dayside (MLT 09-15) than on the nightside (1.9\%, MLT 21-03). The same pattern was observed during low solar activity. When IMF $B_{\mathrm{y}}$ was positive (negative), the high-density region tended to be observed in the dawn side of the Northern (Southern) Hemisphere or in the duskside of the Southern (Northern) Hemisphere.

3. The electron density in the dayside high-plasma-density region was about $1800 \pm 600 \mathrm{~cm}^{-3}$ and a factor of 10 higher than the surrounding density during a period of high solar activity.

4. The electron temperature in the dayside high-plasmadensity region was about $5200 \pm 1200 \mathrm{~K}$, and about $2000-4000 \mathrm{~K}$ lower than in the surrounding region (>8000 K).

5. During a period of high solar activity, the $\mathrm{H}^{+}$ion velocity in the dayside high-plasma-density region was about $5.6 \pm 3.8,6.4 \pm 4.2$, and $6.2 \pm 4.1 \mathrm{~km} \mathrm{~s}^{-1}$, which is 2.2 , 2.0 , and $3.2 \mathrm{~km} \mathrm{~s}^{-1}$ lower than the averaged polar wind $\mathrm{H}^{+}$velocity $\left(7.8 \pm 2.5,8.4 \pm 1.4\right.$, and $\left.9.4 \pm 0.9 \mathrm{~km} \mathrm{~s}^{-1}\right)$ at $3000-4000,4000-5000$, and $5000-6000 \mathrm{~km}$ altitude, respectively. Also, the $\mathrm{O}^{+}$ion composition ratio increased by about 5-10\% in comparison with the averaged ion composition at the same altitude inside the polar cap.

\section{Discussions and conclusion}

Ichikawa et al. (2002) suggested that dense plasma produced by solar EUV photo-ionization in the dayside or by particle precipitation in the cusp can be a possible source for the observed high-density and low-temperature plasma in the highaltitude polar cap. However, the high-density plasma in this study is unlikely to be generated by particle precipitation in the cusp region, because the observed electron temperature is remarkably low. In the present study, a detailed comparison was made of data from Akebono, DMSP F15, ground GPS receiver network and the SuperDARN radar for the event on 20 March 2002, and the comparison suggests that the highdensity low-temperature plasma existing in the high-altitude polar cap is the high-altitude counterpart of the SED/TOI plume. It is known that the SED/TOI can be transported to the dayside cusp region from the dayside mid-latitude region, and can possibly penetrate deep into the central polar cap due to anti-sunward plasma convection. In a similar manner, the low temperature and $\mathrm{O}^{+}$dominant dense plasma observed on Akebono may be transported from the mid-latitude ionosphere or plasmasphere to the polar cap through the cusp.

An important question here is the possible three-way connections between the observed SED/TOI TEC in the topside ionosphere (Region A of Fig. 3), the observed ion velocity and density enhancement in the cusp on DMSP F15 (Region B of Fig. 3), and the observed plasma density enhancement in the high-altitude polar cap on Akebono ( $\mathrm{Re}$ gion C of Fig. 3). The SuperDARN ion convection map in Fig. 3b shows that the convection streamlines traversing Region A of the post-noon cleft region were predominantly 
westward and traversed the lower-latitude portion of Region B of the cusp. Thereafter, the streamlines gradually turned anti-sunward near 09:00 MLT and eventually intersected the higher-latitude portion of Region $\mathrm{C}$ of the polar cap. In the following, we estimate the horizontal ion transit time (i.e. ion convection time) from $\mathrm{A}$ to $\mathrm{B}$ and from $\mathrm{B}$ to $\mathrm{C}$, respectively, in magnetic latitude and local time, $\Delta t_{\mathrm{h}, \mathrm{a} \rightarrow \mathrm{b}}$, and $\Delta t_{\mathrm{h}, \mathrm{b} \rightarrow \mathrm{c}}$, as well as the corresponding vertical ion transit time (i.e. time of vertical ion flow) in altitude, $\Delta t_{z, \mathrm{a} \rightarrow \mathrm{b}}$, and $\Delta t_{z, \mathrm{~b} \rightarrow \mathrm{c}}$.

Between A and B, where the ion convection was predominantly westward, the horizontal ion transit time is approximately

$\Delta t_{\mathrm{h}, \mathrm{a} \rightarrow \mathrm{b}}=\frac{\Delta \mathrm{MLT} \times \Delta r}{v_{\mathrm{h}}}$

$v_{\mathrm{h}}=\frac{v_{\mathrm{h}, \mathrm{a}}+v_{\mathrm{h}, \mathrm{b}}}{2}$

In Eq. (1), $\Delta$ MLT is the separation in MLT, $\Delta r$ is the rate of increase in horizontal spatial distance with MLT separation between $\mathrm{A}$ and $\mathrm{B}$, and $v_{\mathrm{h}}$ is the averaged horizontal ion velocity. In Eq. (2), $v_{\mathrm{h}, \mathrm{a}}$ and $v_{\mathrm{h}, \mathrm{b}}$ are the horizontal ion velocity at region $\mathrm{A}$ and $\mathrm{B}$, respectively; $v_{\mathrm{h}, \mathrm{a}}$ and $v_{\mathrm{h}, \mathrm{b}}$ are assumed to be $0.8 \mathrm{~km} \mathrm{~s}^{-1}$ and $1.5 \mathrm{~km} \mathrm{~s}^{-1}$, respectively, from Fig. $3 \mathrm{~b}$ and Fig. 4 . Thus, $v_{\mathrm{h}} \approx 1.2 \mathrm{~km} \mathrm{~s}^{-1}$. From Fig. $3 \mathrm{~b}$, it can be seen that $\Delta \mathrm{MLT} \approx 3 \mathrm{~h}$ of MLT; and $\Delta r \approx(2 \pi / 24)$ $\left(R_{\mathrm{E}}+z\right) \cos \theta_{\mathrm{m}} \approx 539 \mathrm{~km} \mathrm{~h}^{-1}$ of MLT; $R_{\mathrm{E}}$ is the Earth radius and taken to be $6370 \mathrm{~km}, \theta_{\mathrm{m}}$ is the magnetic latitude and taken to be $73^{\circ}$, and $z$ is the starting altitude of ion up-flow. Based on the study of Ogawa et al. (2009), which showed that the starting altitude of ion up-flow in the dayside cleft region rises to 400 to $450 \mathrm{~km}$ near solar maximum, $z$ is assumed to be $\sim 400 \mathrm{~km}$. Thus, $\Delta t_{\mathrm{h}, \mathrm{a} \rightarrow \mathrm{b}} \approx 0.31 \mathrm{~h}$.

The corresponding vertical ion transit time is approximately

$\Delta t_{z, \mathrm{a} \rightarrow \mathrm{b}}=\frac{z_{\mathrm{b}}-z_{\mathrm{a}}}{v_{z}} \approx \frac{z_{\mathrm{b}}-z_{\mathrm{a}}}{\left(v_{\mathrm{b}}+v_{\mathrm{a}}\right) / 2}$

In Eq. (3), $z_{\mathrm{a}}$ and $z_{\mathrm{b}}$ and $v_{\mathrm{a}}$ and $v_{\mathrm{b}}$ are the altitudes and vertical ion speeds at $\mathrm{A}$ and $\mathrm{B}$, respectively, and $v_{z}$ is the averaged vertical ion speed and is positive upward. Note that although ion up-flow in the cleft ionosphere is primarily field-aligned as opposed to vertical, the DMSP measures the ion velocity in the vertical and horizontal directions, and therefore the ion velocity data in Fig. $4 \mathrm{c}$ is directly applicable to (32). For simplicity, $v_{z}$ is taken to be the average of $v_{\text {a }}$ and $v_{\mathrm{b}}$. From Fig. $4 \mathrm{c}, v_{\mathrm{b}} \approx 0.7 \mathrm{~km} \mathrm{~s}^{-1}$. Since the threshold of ion up-flow velocity at the starting altitude is $0.1 \mathrm{~km} \mathrm{~s}^{-1}$ in Ogawa et al. (2009), we assume $v_{\mathrm{a}} \approx 0.1 \mathrm{~km} \mathrm{~s}^{-1}$ and therefore $v_{z} \approx 0.4 \mathrm{~km} \mathrm{~s}^{-1}$. Using $z_{\mathrm{a}}=400 \mathrm{~km}, z_{\mathrm{b}}=850 \mathrm{~km}$, $\Delta t_{z, \mathrm{a} \rightarrow \mathrm{b}} \approx 0.31 \mathrm{~h}$. The fact that (a) the convection streamlines from Region A traversed the lower-latitude portion of Region B and that (b) the corresponding horizontal and vertical ion transit times are quite comparable is interpreted as a direct evidence of the plasma in the SED/TOI in Region A being the source of plasma observed on DMSP F15 in Region $\mathrm{B}$. The corresponding horizontal and vertical ion transit times were quite comparable; both times are $\sim 0.31 \mathrm{~h}$, but the apparent, close agreement may be fortuitous given the approximate nature of the analysis. As discussed earlier in Sect. 2.2 above, the plume had existed from 14:00 to 15:50. It is therefore reasonable to assume that (a) the TEC distribution in Fig. 3a, which was observed at 15:40-15:45 UT, is representative of that near $15: 25$, i.e. about 20 min before the DMSP F15 observations at 15:45-15:48 in Region B, and that (b) the observed ion velocity variations in Fig. $4 \mathrm{~b}$ and $4 \mathrm{c}$ are primarily spatial in origin.

Likewise, between $\mathrm{B}$ and $\mathrm{C}$, where the ion convection was initially westward but gradually turned anti-sunward, the horizontal ion transit time may be estimated as

$\Delta t_{\mathrm{h}, \mathrm{b} \rightarrow \mathrm{c}}=\Delta t_{\mathrm{h}, \mathrm{b} \rightarrow \mathrm{t}}+\Delta t_{\mathrm{h}, \mathrm{t} \rightarrow \mathrm{c}}$

In Eq. (4), the subscript $t$ denotes the turning point $\mathrm{T}$ in the convection streamlines from westward to anti-sunward near $9 \mathrm{MLT}$, and $\Delta t_{\mathrm{h}, \mathrm{b} \rightarrow \mathrm{t}}$ and $\Delta t_{\mathrm{h}, \mathrm{t} \rightarrow \mathrm{c}}$ denote the transit times from $\mathrm{B}$ to $\mathrm{T}$ and from $\mathrm{T}$ to $\mathrm{C}$, respectively, i.e.

$$
\begin{aligned}
& \Delta t_{\mathrm{h}, \mathrm{b} \rightarrow \mathrm{t}}=\frac{\Delta \mathrm{MLT} \times \Delta r}{v_{\mathrm{h}}} \\
& \Delta t_{\mathrm{h}, \mathrm{t} \rightarrow \mathrm{c}}=\frac{\Delta \mathrm{MLAT} \times \Delta r^{\prime}}{v_{\mathrm{h}}}
\end{aligned}
$$

In Eq. (5), $\Delta$ MLT, $\Delta r$ and $v_{\mathrm{h}}$ have the same meanings as in Eq. (1). From Fig. $3 \mathrm{~b}$, it can be seen that $\Delta \mathrm{MLT} \approx 2 \mathrm{~h}$ of MLT, $v_{\mathrm{h}} \approx 1.5 \mathrm{~km} \mathrm{~s}^{-1}$ at the DMSP altitude, and $\Delta r \approx$ $539 \mathrm{~km} \mathrm{~h}$ of MLT as before. Thus, $\Delta t_{\mathrm{h}, \mathrm{b} \rightarrow \mathrm{t}} \approx 0.21 \mathrm{~h}$. In Eq. (6), $\triangle$ MLAT is the separation in magnetic latitude, $\Delta r^{\prime}$ is the rate of increase in horizontal spatial distance with magnetic latitude separation, and $v_{\mathrm{h}}$ is the horizontal ion velocity between T and C. From Fig. 3b, it can be seen that $\mathrm{T}$ and $\mathrm{C}$ are located near $73^{\circ}$ and $80^{\circ}$ MLAT, respectively, $\Delta$ MLAT $\approx 8^{\circ}$, and $\Delta r^{\prime} \approx(2 \pi / 360)\left(R_{\mathrm{E}}+z\right) \approx$ $115 \mathrm{~km} \mathrm{deg}^{-1} ; z$ is again taken as $\sim 250 \mathrm{~km}$. Assuming $v_{\mathrm{h}} \approx 1.5 \mathrm{~km} \mathrm{~s}^{-1}$ at the DMSP altitude in the region of antisunward flow also, $\Delta t_{\mathrm{h}, \mathrm{t} \rightarrow \mathrm{c}} \approx 0.18 \mathrm{~h}$. Thus, $\Delta t_{\mathrm{h}, \mathrm{b} \rightarrow \mathrm{c}} \approx$ $0.39 \mathrm{~h}$.

The vertical ion transit time from B to $\mathrm{C}$ is approximately

$\Delta t_{z, \mathrm{~b} \rightarrow \mathrm{c}}=\frac{z_{\mathrm{c}}-z_{\mathrm{b}}}{v_{z}}=\frac{z_{\mathrm{c}}-z_{\mathrm{b}}}{\left(v_{\mathrm{b}}+v_{\mathrm{c}}\right) / 2}$

In Eq. (7), $z_{\mathrm{b}}$ and $z_{\mathrm{c}}$ and $v_{\mathrm{b}}$ and $v_{\mathrm{c}}$ are the altitudes and vertical ion speeds at $\mathrm{B}$ and $\mathrm{C}$, respectively, and $v_{z}$ is the averaged vertical ion speed between the two points. For simplicity, we assume $v_{z}$ to be the mean between the observed velocities on DMSP F15 and Akebono, respectively. From Figs. $4 \mathrm{c}$ and $1 \mathrm{~d}$ (in the absence of ion velocity data in Fig. 2), $v_{\mathrm{b}} \approx 0.7 \mathrm{~km} \mathrm{~s}^{-1}$ and $v_{\mathrm{c}} \approx 2 \mathrm{~km} \mathrm{~s}^{-1}$. Using $z_{\mathrm{b}}=850 \mathrm{~km}, z_{\mathrm{c}}=3500 \mathrm{~km}$, and $v_{z} \approx 1.4 \mathrm{~km} \mathrm{~s}^{-1} \Delta t_{z, \mathrm{~b} \rightarrow \mathrm{c}} \approx 0.52 \mathrm{~h}$. The fact that the convection streamlines from the lower-latitude portion of Region $\mathrm{B}$ 
traversed the higher-latitude portion of Region $\mathrm{C}$ and that the corresponding horizontal and vertical ion transit times were quite comparable ( 0.39 versus $0.52 \mathrm{~h})$ is interpreted as a direct evidence of the ion up-flow observed on DMSP F15 at $850 \mathrm{~km}$ altitude in the cusp being the source of enhanced plasma density observed on Akebono in the high-altitude polar cap, assuming, as noted above, the ion velocity variations observed on DMSP F15 to be primarily spatial.

The important role of the polar ionosphere as a source of plasma to the magnetosphere has been the subject of several studies on the origin of magnetospheric plasma. Various types of ion upflows and outflows are known to exist in the polar ionosphere, and these include the polar wind, ion conics, ion beam, the cleft ion fountain (CIF) and so on. The terms "ion upflow" and "ion outflow" are used in the literature (e.g., Yau and André, 1997) to describe ion flows whose velocity is lower and higher than the escape velocity, respectively, the latter being sufficiently energetic to flow out to the magnetosphere at higher altitude. The CIF (Lockwood et al., 1985) is caused by ion heating due to particle precipitation and electromagnetic waves, and is also one of the important outflow mechanisms from the cusp/cleft region. Zeng and Horwitz (2008) suggested that the ion outflow flux can be intensified by the CIF when the SED plume penetrates into the cusp/cleft region. Schunk et al. (2005) also showed that the ion outflow rate due to the polar wind is increased by the penetration of the SED/TOI plume to the polar cap. Using ion drift data from the DMSP satellite observations, Yuan et al. (2008) reported that significant plasma upflow may exist on the nightside when the SED/TOI plume is heated by particle precipitation after it penetrates the boundary between the polar cap and the aurora oval on the nightside by antisunward convection. They also proposed a possible contribution of such a plasma upflow to the ring current and the plasmasheet on the night side.

As discussed above, the low-temperature high-density plasma observed by Akebono above $3000 \mathrm{~km}$ on 20 March 2002 is likely connected with the TOI plume at the F-region altitude through convecting magnetic field lines; in other words, the former is considered the high-altitude counterpart of the latter. The electron temperature inside the SED was found to be low based on Millstone Hill radar observations (Foster, 1993), and it was likewise very low inside the high density plasma region at Akebono altitude. Thus, low electron temperature is a common feature between SED/TOI plumes and high-altitude, high-density plasma regions.

As noted in Sect. 2.3 above, the occurrence probability of the high-altitude large plasma-density events is higher during the high solar activity period, when the electron density is generally higher, compared with the low activity period. This result may be an effect of the instrument's detection sensitivity. Furthermore, the occurrence probability is higher during active times $(\mathrm{Kp} \geq 4)$ compared to quiet times $(\mathrm{Kp}<2)$, and it becomes much higher during very active times $(\mathrm{Kp} \geqq 6)$.

The high-plasma-density region is more frequently ob- served on the duskside than on the dawnside. Our statistical analysis shows that the sector of event occurrence depends on the polarity of IMF $B_{\mathrm{y}}$, and is on dawn side of the Northern (Southern) Hemisphere and the duskside of the Southern (Northern) Hemisphere during positive (negative) IMF $B_{\mathrm{y}}$. This may be related to the IMF $B_{\mathrm{y}}$ asymmetry of enhanced electron densities observed around magnetic noon (Moen et al., 2008).The Akebono observation indicates that the upward velocity of the $\mathrm{H}^{+}$ion inside the high-density region is significantly lower than in the adjacent region (see Fig. 1d). This means that ambipolar electric field inside the region is perhaps not as strong as those in the adjacent region and therefore the ions inside the region are accelerated to lower velocities than typically measured at the same altitudes on Akebono. Figure 4 suggests that the plasma transported from the lower latitude side may have been energized to some degree by some mechanisms such as soft electron precipitation and/or plasma wave in the ionospheric cusp region, and thereby attained upward velocity of $\sim 500 \mathrm{~m} \mathrm{~s}^{-1}$. However, the ion velocity and electron temperature observed by Akebono at $5000 \mathrm{~km}$ are significantly lower than the average values, and this suggests the absence of any heating and energization inside the high-density plasma region at higher altitudes. In other words, the ion heating or acceleration process was apparently operative at low altitude region only, and the ion velocity at high altitudes $(\sim 5000 \mathrm{~km})$ was probably driven by different processes. In this regard, the low electron temperature is consistent with the low ion velocity, since the ambipolar electric field responsible for polar wind ion acceleration is in general proportional to the electron plasma pressure gradient, i.e. to the electron temperature for a given plasma density gradient and plasma density gradient for a given electron temperature; therefore, significant polar wind ion acceleration via ambipolar electric field is unlikely to occur inside the high-density plasma flux tube, at least up to Akebono altitudes.

Ichikawa et al. (2002) suggested that the low electron temperature is responsible for the low velocity of ions in the high-density plasma region. The combination of low electron temperature and small plasma pressure gradient can give rise to only a small ambipolar electric field and a low ion velocity, and both of these two characteristics are typical of plasma in closedmagnetic flux tubes. The fact that no polar wind was observed in the high-density region is consistent with the suggestion that these plasmas originated from the mid-latitude or plasmasphere.

Our statistical analysis of Akebono observations shows that the high density plasma at high altitude is more frequently observed in the dayside than in the nightside, as discussed in Sect. 2.3. This may be attributed to a gradual decrease of the plasma density at Akebono altitudes due to upward ion transport and/or field-aligned diffusion during the anti-sunward convection of the SED plumes toward nightside and/or to a gradual descent of $\mathrm{O}^{+}$dominant dense plasma due to gravitational force. 
An important statistical feature of the local plasma density enhancements observed by Akebono is that the $\mathrm{O}^{+}$ions are dominant over $\mathrm{H}^{+}$ions in the high-density plasma region, compared to the averaged ion composition at the same altitude inside the polar cap. It is generally thought that heavy ions such as $\mathrm{O}^{+}$are dominant in the polar cap, where the light ions are transported upward by polar wind acceleration along open magnetic field lines. However, such a scenario is inconsistent with Akebono observations showing the absence of polar wind flows in high-density regions of the polar cap. Therefore, the $\mathrm{O}^{+}$dominant high-density plasma regions may have originated from the low-altitude mid-latitude (closed field line) region where the $\mathrm{O}^{+}$ions are dominant. If this is the case, an intense flux of upwelling ions may occur in the low-altitude cusp region and convect to the polar cap due to anti-sunward convection. A quantitative analysis using particle trajectory simulations will be needed for a further understanding of the source and transport of such regions.

Acknowledgements. We wish to acknowledge Akebono science team members for their continuous support for the satellite operation. We would like to thank the Center for Space Sciences at the University of Texas at Dallas and Marc Hairston for the use of the DMSP ion velocity and density data. The DMSP particle detectors were designed by Dave Hardy of AFRL, and the data were obtained by JHU/APL. We also wish to thank Dave Hardy and JHU/APL for electron energy flux data. We would like to thank A. Coster for providing GPS TEC data of the Madrigal database at Haystack observatory. The data from the SuperDARN Goose Bay, Hankasalmi, Kapuskasing, Kodiak, King Salmon, Prince George, Pykkvibaer, Saskatoon and Stokkseyri radars were utilized to calculate the global convection map; we thank the people who contributed to the construction and operation of these radars and also the funding agencies of these radars. We also thank the funding support of the Canadian Space Agency and the Natural Science and Engineering Research Council Industrial Research Chair program.

Topical Editor K. Kauristie thanks two anonymous referees for their help in evaluating this paper.

\section{References}

Abe, T., Oyama, K. I., Amemiya, H., Watanabe, S., Okuzawa, T., and Schlegel, K.: Measurements of temperature and velocity distribution of thermal electrons by Akebono (EXOS-D) satellite, J. Geomag. Geoelectr., 42, 537-554, 1990.

Abe, T., Whalen, B. A., Yau, A. W., Horita, R. E., Watanabe, S., and Sagawa, E.: EXOS D (Akebono) Suprathermal mass spectrometer observations of the polar wind, J. Geophys. Res., 98(A7), 11191-11203, 1993a.

Abe, T., Whalen, B. A., Yau, A. W., Watanabe, S., Sagawa, E., and Oyama, K. I.: Altitude profile of the polar wind velocity and its relationship to ionospheric conditions, Geophys. Res. Lett., 20(24), 2825-2828, 1993b.

Chandler, M. O., Waite Jr., J. H., and Moore, T. E.: Observations of polar ion outflows, J. Geophys. Res., 96, 1421-1428, 1991.

Coley, W. R. and Heelis, R. A.: Adaptive identification and characterization of polar ionization patches, J. Geophys. Res., 100, 23819-23828, 1995.
Foster, J. C.: Storm-time plasma transport at middle and high latitudes, J. Geophys. Res., 98, 1675-1689, 1993.

Foster, J. C., Erickson, P. J., Coster, A. J., Goldstein, J., and Rich, F. J.: Ionospheric signatures of plasmaspheric tails, Geophys. Res. Lett., 29(13), 1623, doi:10.1029/2002GL015067, 2002.

Foster, J. C., Erickson, P. J., Coster, A. J., Rich, F. J., and Sandel, B. R.: Stormtime observations of the flux of plasmaspheric ions to the dayside cusp/magnetopause, Geophys. Res. Lett., 31, L08809, doi:10.1029/2004GL020082, 2004.

Foster, J. C., Coster, A. J., Erickson, P. J., Holt, J. M., Lind, F. D., Rideout, W., McCready, M., van Eyken, A. P., Barnes, R. J., Greenwald, R. A., and Rich, F. J.: Multiradar observations of the polar tongue of ionization, J. Geophys. Res., 110, A09S31, doi:10.1029/2004JA010928, 2005.

Hosokawa, K., Tsugawa, T., Shiokawa, K., Otsuka, Y., Nishitani, N., Ogawa, T., and Hairston, M. R.: Dynamic temporal evolution of polar cap tongue of ionization during magnetic storm, J. Geophys. Res., 115, A12333, doi:10.1029/2010JA015848, 2010.

Ichikawa, Y., Abe, T., and Yau, A. W.: Plasma density enhancements in the high-altitude polar cap region observed on Akebono, Geophys. Res. Lett., 29(9), 1327, doi:10.1029/2001GL013723, 2002.

Kitamura, N., Shinbori, A., Nishimura, Y., Ono, T., Iizima, M., and Kumamoto, A.: Seasonal variations the electron density distribution in the polar region during geomagnetically quiet periods near solar maximum, J. Geophys. Res., 114, A01206, doi:10.1029/2008JA013288, 2009.

Kletzing, C. A., Mozer, F. S., and Torbert, R. B.: Electron temperature and density at high latitude, J. Geophys. Res., 103, 1483714846, 1998.

Lockwood, M., Waite Jr., J. H.,, Moore, T. E., Chappell, C. R., and Chandler, M. O.: The cleft ion fountain, J. Geophys. Res., 90, 9736-9748, 1985.

Moen, J., Qiu, X. C., Carlson, H. C., Fujii, R., and McCrea, I. W.: On the diurnal variability in F2-region plasma density above the EISCAT Svalbard radar, Ann. Geophys., 26, 2427-2433, doi:10.5194/angeo-26-2427-2008, 2008.

Ogawa, Y., Haggstrom, I., Buchert, S. C., Oksavik, K., Nozawa, S., Hirahara, M., van Eyken, A. P., Aso, T., and Fujii, R.: On the source of the polar wind in the polar topside ionosphere: First results from the EISCAT Svalbard radar, Geophys. Res. Lett., 36, L24103, doi:10.1029/2009GL041501, 2009.

Persoon, A. M., Gurnett, D. A., and Shawhan, S. D.: Polar cap electron densities from DE 1 plasma wave observations, J. Geophys. Res., 88, 10123-10136, 1983.

Rideout, W. and Coster, A.: Automated GPS processing for global total electron content data, GPS Solut, 10(3), 219-228, doi:10.1007/s10291-006-0029-5, 2006.

Ruohoniemi, J. M. and Baker, K. B.: Large-scale imaging of highlatitude convection with Super Dual Auroral Radar Network HF radar observations, J. Geophys. Res., 103(A9), 20797-20811, 1998.

Schunk, R. W., Demars, H. G., and Sojka, J. J.: Propagating polar wind jets, J. Atmos. Solar Terr. Phys., 67, 357-364, 2005.

Su, Y. J., Horwitz, J. L., Moore, T. E., Giles, B. L., Chandler, M. O., Craven, P. D., Hirahara, M., and Pollock, C. J.: Polar wind survey with the thermal ion dynamics experiment/plasma source instrument suite aboard POLAR, J. Geophys. Res., 103, 2930529337, 1998. 
Su, Y. J., Thomsen, M. F., and Borovsky, J. E.: A linkage between polar patches and plasmaspheric drainage plumes, Geophys. Res. Lett., 28(1), 111-113, 2001.

Weber, E. J., Buchau, J., Moore, J. G., Sharber, J. R., Livingston, R. C., Winningham, J. D., and Reinisch, B. W.: F layer ionization patches in the polar cap, J. Geophys. Res., 89, 1683-1694, 1984.

Whalen, B. A., Burrows, J. R., Yau, A. W., Budzinski, E. E., and Pilon, A. M.: The suprathermal ion mass spectrometer (SMS) on board the Akebono (EXOS-D) satellite, J. Geomag. Geoelectr., 42, 511-536, 1990.

Yau, A. W. and André, M.: Source of ion outflow in the high latitude ionosphere, Space Sci. Rev., 80, 1-25, 1997.
Yuan, Z. G., Deng, X. H., and Wang, J. F.: DMSP/GPS observations of intense ion upflow in the midnight polar ionosphere associated with the SED plume during a super geomagnetic storm, Geophys. Res. Lett., 35, L19110, doi:10.1029/2008GL035462, 2008.

Zeng, W. and Horwitz, J. L.: Storm enhanced density (SED) as possible sources for Cleft Ion Fountain dayside ionospheric outflows, Geophys. Res. Lett., 35, L04103, doi:10.1029/2007GL032511, 2008. 